\title{
Cooperation of FGF/MEK/ERK and Wnt/ $\beta$-catenin pathway regulators to promote the proliferation and pluripotency of mouse embryonic stem cells in serum- and feeder-free conditions
}

Tong Zhang, Huanyun Chen, Yiran Zhou, Wanghong Dong, Haibo Cai* and Wen-Song Tan

\begin{abstract}
The FGF/MEK/ERK and Wnt/ $\beta$-catenin signaling pathways have previously been proved to regulate mouse embryonic stem cell (mESCs) function. However, the relationships between these two pathways, especially their different functions on proliferation and pluripotency of $\mathrm{mESCs}$, were rarely mentioned. Here, we investigated the effects of FGF/MEK/ERK and Wnt/ $\beta$-catenin pathway regulators and their combinations on the proliferation and pluripotency of mESCs under serum- and feeder-free conditions. We found that MEK inhibitor PD0325901 and FGFR inhibitor SU5402 has paradoxical function on mESCs; one could promote proliferation along with differentiation and the other one could improve pluripotency while impairing cell proliferation. The combination of these two kinds of inhibitors could better regulate FGF/MEK/ERK pathway. Wnt/ $\beta$-catenin pathway regulators SB216763 led to differentiation while promoting proliferation of $\mathrm{mESC}$. When we used FGF/MEK/ERK and Wnt/ $\beta$-catenin pathway regulators in combination, the total expansion fold of mESCs reached $318.78 \pm 47.95$ and the proportion of SSEA-1-positive cells reached $82.40 \pm 2.74 \%$ which were significantly higher than using the regulators alone. This finding indicates that regulators of FGF/MEK/ERK and Wnt/ $\beta$-catenin pathways play different roles in the regulatory networks of mESCs. Their combination can better maintain the undifferentiated state and promote the proliferation of mESCs under serum- and feederfree conditions.
\end{abstract}

Keywords: mESCs, FGF/MEK/ERK pathway, Wnt/B-catenin pathway, Small molecule regulator, In vitro proliferation

\section{Introduction}

Embryonic stem cells (ESCs) have extraordinary potential for application in cell therapy and regenerative medicine because of their ability to differentiate into almost all cell types. However, the amount of ESCs is limited and the pluripotent state cannot be maintained for a long time in vitro, especially in serum- and feeder-free culture conditions (Volarevic et al. 2018). To solve this problem, much effort has been devoted (Evans and Kaufman 1981; Yang et al. 2010; Volarevic et al. 2011). Extensive studies

\footnotetext{
*Correspondence: caihaibo@ecust.edu.cn

State Key Laboratory of Bioreactor Engineering, East China University of Science and Technology, Shanghai 200237, China
}

have shown that the regulation of signaling pathways has a significant effect on cell fate decisions of ESCs, among which the FGF/MEK/ERK pathway and the Wnt/ $\beta$ catenin pathway are receiving more and more attention (Chen et al. 2007; van Amerongen 2009).

Wnt pathways are critical for developmental processes including self-renewal, cell proliferation and pluripotency in many types of stem cells (Kleber and Sommer 2004; Dravid et al. 2005; ten Berge et al. 2011; Kirby et al. 2012). It is characterized by the stabilization of intracellular $\beta$-catenin. The stabilization and upregulation of $\beta$-catenin enhance E-cadherin expression on the cell membrane, thereby enhancing ESCs self-renewal through E-cadherin-associated PI3K/Akt signaling (Huang et al. 2015). 
Glycogen synthase kinase-3 (GSK-3) phosphorylates $\beta$-catenin, making it a target for ubiquitination and subsequent proteasome-mediated degradation, inducing cell differentiation (Akiyama 2000; Asuni et al. 2006; Kimelman 2006; MacDonald and He 2009). GSK-3 inhibitors activate Wnt pathway and ultimately prevent $\beta$-catenin degradation. Some studies showed that GSK3 inhibitors can enhance the propagation and upregulate the expressions of pluripotency markers of ESCs such as Oct4 and Nanog under serum- and feeder-free conditions (Sato et al. 2004, 2009; Nagai et al. 2014). Other reports showed that Wnt pathway stimulates G1 to $S$ phase cell cycle progression and contributes to cell proliferation (Yun et al. 2005). Yet, paradoxically, the more selective GSK3 inhibitor CHIR99021 has been shown to induce non-neural differentiation of mESCs under serum- and feeder-free conditions (Ying et al. 2008; Kirby et al. 2012). Sumi et al. showed that activation of Wnt pathway and stabilized $\beta$-catenin perturbed ESCs self-renewal and led to mesenchymal transition (EMT) (Sumi et al. 2008).

Many reports have mentioned the role of the FGF/ MEK/ERK pathway in the proliferation and differentiation of ESCs (Kunath et al. 2007; Li et al. 2007; Ying et al. 2008). Activation of fibroblast growth factor receptor (FGFR) stimulates a multitude of downstream signaling cascades (Kim and Nishida 2001). A main pathway is mitogen-activated protein kinase (MEK)/extracellular signal-regulated kinase (ERK) signaling pathway which can be effectively regulated by FGFR inhibitors and MEK inhibitors (Ma et al. 2016). Some reports showed that specific inhibitor of MEK can effectively inhibit the phosphorylation of ERK and thereby contribute to the maintenance of mESC pluripotency (Burdon et al. 1999; Kunath et al. 2007; Yu et al. 2018). In addition, knockout of the upstream activator FGFR for ERK signaling impairs the neural differentiation of ESCs (Kunath et al. 2007), while the specific FGFR inhibitor SU5402 leads to rapid differentiation of ESCs (Kim and Nishida 2001; Dvorak et al. 2006).

Ying et al. first proposed that the combination of inhibitors of the FGF/MEK/ERK and GSK3 $\beta$ could maintain the pluripotency of mESCs under serumfree medium with/without LIF, but colonies cultured without LIF have poor proliferation rate (Ying et al. 2008; En-Shu et al. 2011). Kiyonari et al. proved that the combination of FGF/MEK/ERK and GSK3 $\beta$ inhibitors establishes germline-competent embryonic stem cells of C57BL/6N mouse strain with high efficiency and stability (Kiyonari et al. 2010; Nichols and Jones 2017). However, the relationship between FGF/MEK/ ERK and Wnt/ $\beta$-catenin pathways, especially their different functions on proliferation and pluripotency of mESCs between individual and joint regulation, was rarely mentioned. Here, we investigated the effects of FGF/MEK/ERK and Wnt/ $\beta$-catenin pathway regulators and their combinations on the proliferation and pluripotency of mESCs under serum- and feeder-free conditions to better understand the complex regulatory network of ESCs. The proliferation and pluripotency data were closely monitored each passage in the culture process.

\section{Methods \\ Cell culture}

mESCs lines (129 strain) were cultured in DMEM (Gibco, CA, USA) with 15\% knockout serum replacement (KSR, Invitrogen, NY, USA), 1\% L-Glutamax (Sigma-Aldrich, Munich, Germany), 0.1 mM 2-mercaptoethanol (SigmaAldrich, Munich, Germany), $1 \%$ nonessential amino acids (NEAA) (Sigma-Aldrich, Munich, Germany), 1\% penicillin/streptomycin (Sigma-Aldrich, Munich, Germany) and $10 \mathrm{ng} / \mathrm{mL}$ LIF (Peprotech, NJ, USA). After passaging, cells were seeded in $0.1 \%$ gelatin-coated 6 -well plates at a density of $5 \times 10^{4} \mathrm{cell} / \mathrm{cm}^{2}$. For signaling pathway regulators, GSK3 inhibitor (SB216763), FGFR inhibitor (SU5402) and MEK inhibitor (PD0325901) used here (Sigma-Aldrich, Munich, Germany) were added in accordance with the concentration of $5 \mu \mathrm{M}, 2 \mu \mathrm{M}$ and $1 \mu \mathrm{M}$, respectively (Coghlan et al. 2000; Ying et al. 2008; Zhang 2010). mESCs were cultured for three passages (3 days per passage) in the presence of inhibitors alone or in combination. The proliferation of cells was evaluated by fold expansion in each passage and total fold expansion after three passages. The calculation formulas were listed below.

Fold expansion in each passage $=$ Number of cells harvested/Number of cells seeded in each passage.

Total fold expansion $=$ Product of fold expansion of 3 passages.

\section{SSEA-1-positive cell analysis with flow cytometry}

Stage-specific embryonic antigen-1 (SSEA-1) is a specific pluripotent surface marker of mESCs and the proportions of SSEA-1-positive cells can be detected by flow cytometry. Briefly, more than $10^{6}$ cells were collected, rinsed with PBS (phosphate buffer) and then incubated with anti-mouse SSEA- 1 antibody (BD, CA, USA) at $4{ }^{\circ} \mathrm{C}$ for $30 \mathrm{~min}$ in the dark. $10^{4}$ events were acquired on an FACS Canto and the percentage of SSEA-1-positive cells was analyzed with CellQuest software.

Percentage of SSEA-1-positive cells $=\%$ parent (Q1+Q2).

Fold expansion of SSEA-1-positive cells $=$ Total fold expansion $\times$ Percentage of SSEA-1-positive cells. 


\section{Alkaline phosphatase staining}

As a marker of undifferentiated mESCs, alkaline phosphatase staining was performed after fixing the cells with 4\% paraformaldehyde, using a kit (Beyotime, Shanghai, China) following the manufacturer's instruction.

\section{Immunofluorescence analysis of OCT4 expression}

Cells were fixed in $4 \%$ paraformaldehyde for $30 \mathrm{~min}$ at room temperature and treated with $0.2 \%$ Triton X-100/ PBS for $10 \mathrm{~min}$, and then $1 \%$ BSA solution for $30 \mathrm{~min}$ at room temperature. Treated samples were exposed to primary antibody solution against OCT4 (1:200, Millipore, MA, USA) overnight at $4{ }^{\circ} \mathrm{C}$ and then washed three times with PBS for 3 min each. The cells were then incubated with rhodamine-labeled secondary antibody (1:500, Millipore, MA, USA) for $2 \mathrm{~h}$ at room temperature. The cells were then rinsed 3 times in PBS followed by brief incubation in DAPI (1:1000, Sigma-Aldrich, Munich, Germany) for nuclear staining. Images were analyzed by fluorescence microscope.

\section{Oct4, Nanog and Sox 2 confirmation by semi-quantitative PCR}

The pluripotent-specific genes Oct4, Sox2, and Nanog were confirmed by semi-quantitative RT-PCR analysis. $10^{6} \mathrm{mESCs}$ were collected to extract RNA. $1 \mu \mathrm{g}$ RNA was incubated at $70^{\circ} \mathrm{C}$ for $5 \mathrm{~min}$, at $37^{\circ} \mathrm{C}$ for $60 \mathrm{~min}$ and then at $95^{\circ} \mathrm{C}$ for $5 \mathrm{~min}$ to yield cDNA. PCR products were visualized on a $2 \%$ agarose gel by ethidium bromide staining. For primer sequences, please refer to Table 1.

\section{Statistical analysis}

Statistical significance was determined by Student's twotailed $\mathrm{T}$ test for unequal variances. $P$ values $<0.05$ were considered to be statistically significant.

\section{Results}

Effects of MEK and FGFR inhibitors on mESCs proliferation and pluripotency

MEK inhibitor PD0325901 and FGFR inhibitor SU5402 were used alone and in combination to investigate the

Table 1 RT-PCR primer sequences

\begin{tabular}{lll}
\hline Gene & Sequences $\left(\mathbf{5}^{\prime} \boldsymbol{\rightarrow} \mathbf{3}^{\prime} \mathbf{)}\right.$ & \\
\hline GAPDH & F:AACTTTGGCATTGTGGAAGGGCTC & R:TGGAAGAGTGGGAGT \\
& & TGCTGTTGA \\
Nanog & F:TCGAATTCTGGGAACGCCTCATCA & R:CCGCTTGCACTTCAT \\
& & CCTTTGGTT \\
Oct4 & F:AAAGCCCTGCAGAAGGAGCTAGAA & R:TCTCATTGTTGTCGG \\
& & CTTCCTCCA \\
Sox2 & F:AGAGCAAGTACTGGCAAGACCGTT & R:TACATGGATTCTCGG \\
& & CAGCCTGAT \\
\hline
\end{tabular}

effect of FGF/MEK/ERK pathway on mESCs proliferation and pluripotency. We found that the serum- and feeder-free medium without any inhibitors was far from sufficient to support long-term proliferation of mESCs due to the gradually decrease of fold expansion in each passage along with culture (Fig. 1a). The use of PD0325901 alone had little effect on mESCs proliferation and the cell expansion folds only reached $27.83 \pm 14.00$, lower than control $(46.14 \pm 14.37)$. SU5402 alone or PD0325901 + SU5402 increased the cell expansion folds to $126.95 \pm 35.96$ and $125.98 \pm 31.79$, respectively, which were significantly higher than control (Fig. 1b).

The percentage of SSEA-1-positive cells shows that SU5402 alone was useless to improve mESCs pluripotency, while PD0325901 alone or PD0325901 + SU5402 increased the percentage of SSEA-1-positive cells to $87.44 \pm 2.13 \%$ and $81.75 \pm 1.20 \%$, which were significantly higher than the control (61.28 $\pm 7.68 \%)$ (Fig. 2a).

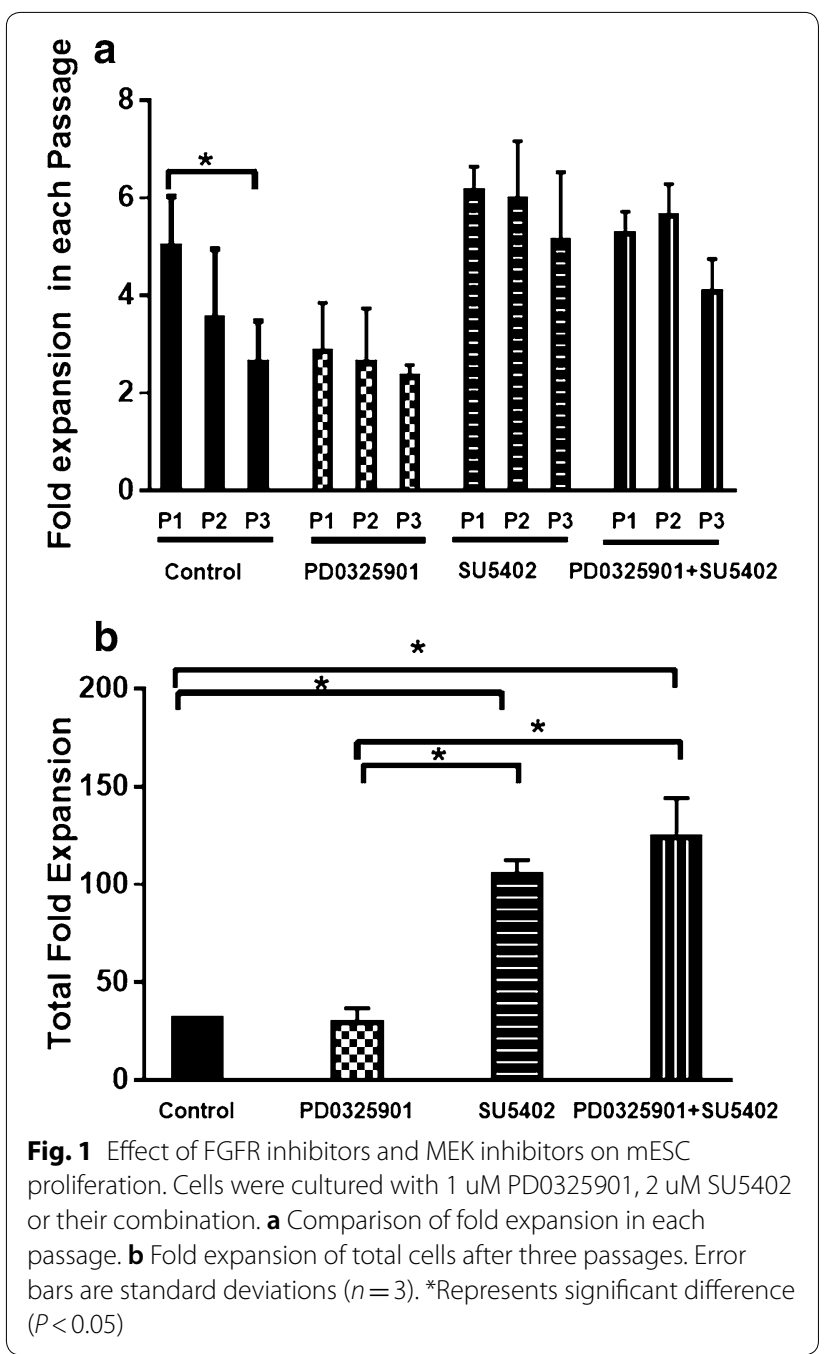


The fold expansion of SSEA-1-positive cells (Fig. 2b) shows similar trend to total cell expansion (Fig. 1b).

The pluripotency of mESCs was further analyzed through alkaline phosphatase staining and immunofluorescence analysis of OCT4 (Fig. 3). It can be observed that mESCs in groups PD0325901 and SU5402 + PD0325901 yielded more compact colonies, whereas mESCs in control group and SU5402 group yielded irregularly shaped colonies and rare OCT4-positive cells.

Therefore, the use of MEK inhibitor PD0325901 can maintain the pluripotency of mESCs but has little effect on proliferation. In contrast, the use of FGFR inhibitor SU5402 can promote the proliferation of mESCs but does not help to maintain the pluripotency of mESCs. It

a

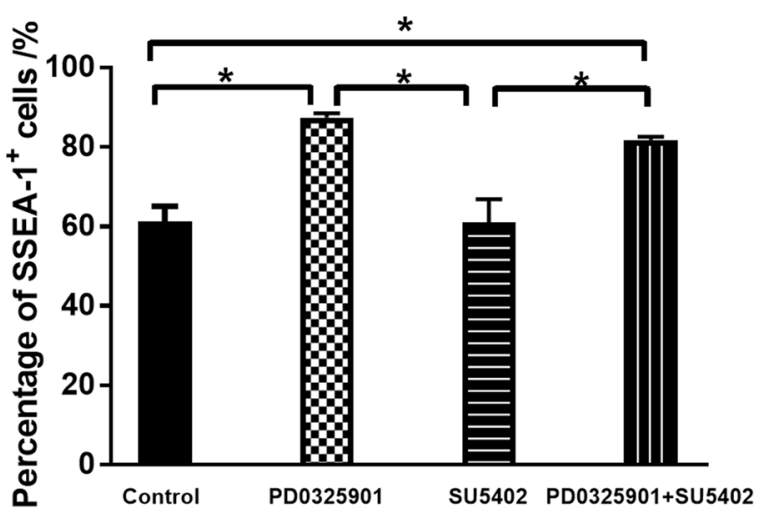

b

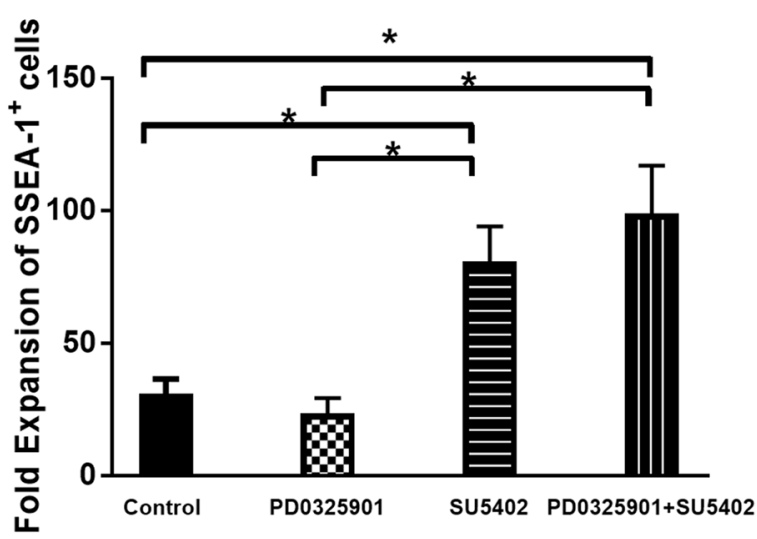

C
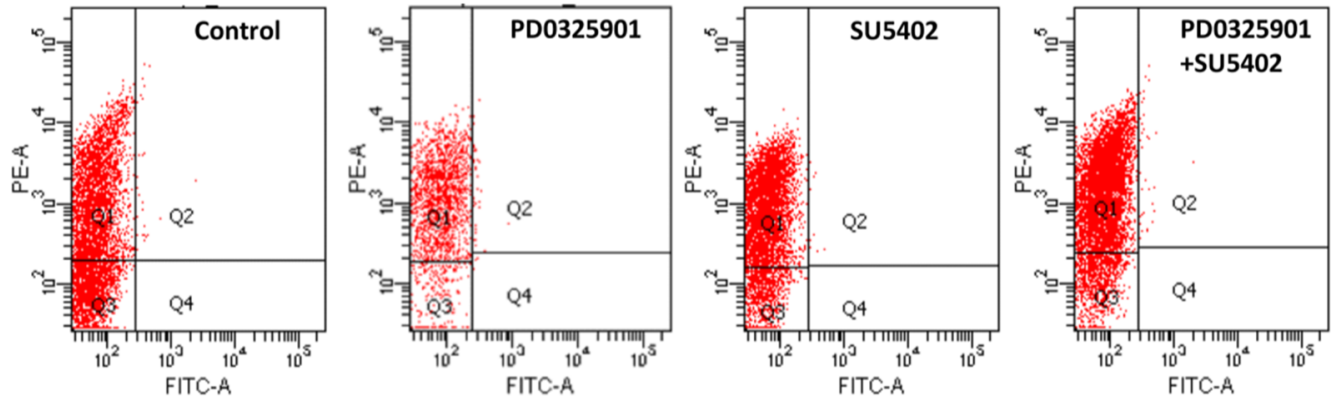

Fig. 2 Effect of FGFR inhibitors and MEK inhibitors on mESC pluripotency. Cells were cultured with 1 uM PD0325901, 2 uM SU5402 or their combination. a The percentage of SSEA-1 ${ }^{+}$cells after 3 passages. b Fold expansion of SSEA-1 ${ }^{+}$cells after three passages. $\mathbf{c}$ Signal threshold for SSEA $-1^{+}$cell in flow cytometry. Error bars are standard deviations $(n=3)$. *Represents significant difference $(P<0.05)$ 


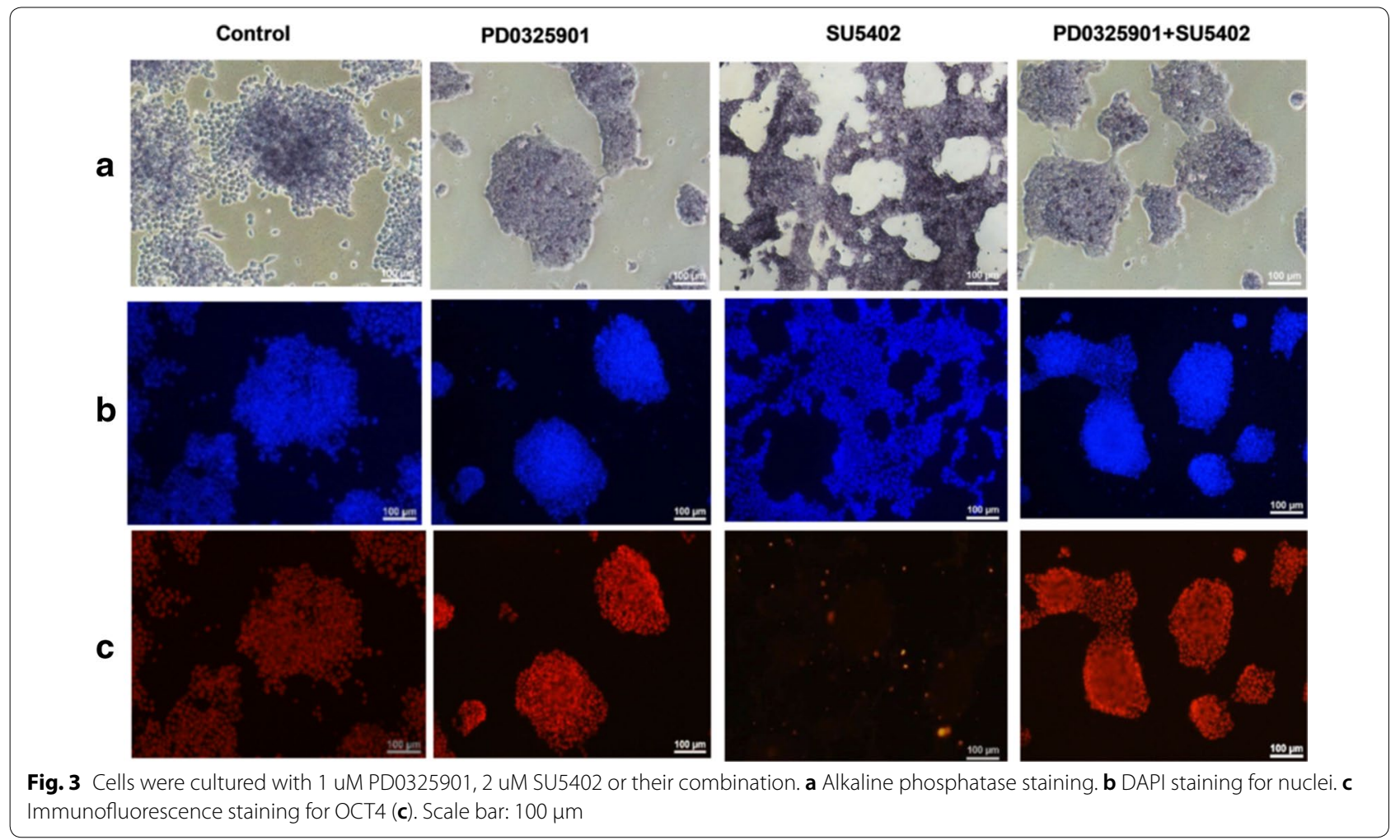

is worth noting that the combination of MEK inhibitors and FGFR inhibitors promotes both proliferation and pluripotency of mESCs, which is far better than using them alone.

\section{Synergistic effects of FGF/MEK/ERK pathway and $W n t / \beta$-catenin pathway on $\mathrm{mESCs}$ proliferation and pluripotency}

To gain a deeper understanding of the interaction between FGF/MEK/ERK pathway and Wnt/ $\beta$-catenin pathway on mESCs proliferation and pluripotency, the regulators of these 2 pathways were used alone and in combination. The experiment groups were as follows: Group a (no treatment), Group b (SB216763), Group c (PD0325901+SU5402), Group d (PD0325901+SU5 $402+$ SB216763). From the result, we found that all the groups except the control group maintained relatively stable fold expansion in each passage (Fig. 4A). After three passages culture, cells in group $b$ showed similar expansion fold to group $\mathrm{c}$ and both were significantly higher than Group a (Fig. 4B). While the proportion of SSEA-1-positive cells of group b significantly reduced from $61.28 \pm 7.68$ to $47.33 \pm 2.00 \%$ (Fig. $5 \mathrm{~B}$ ), indicating that the addition of $\mathrm{Wnt} / \beta$-catenin pathway regulator SB216763 alone can promote the proliferation of mESCs, but resulted in a pluripotency reduction.
Interestingly, when the cells were treated with FGF/ MEK/ERK and Wnt/ $\beta$-catenin pathway regulators together (Group $\mathrm{d}$ ), the fold expansion of total cells reached $318.78 \pm 47.95$, which was significantly higher than the other three groups (Fig. 4B). The proportion of SSEA-1-positive cells reached $82.40 \pm 2.74 \%$, which was significantly higher than Group a and b (Fig. 5A). The fold expansion of SSEA-1-positive cells also shows the same result that the combination of two signal pathway regulators obtains the best effect in pluripotency and proliferation (Fig. 5B).

To further explore the pluripotency of mESCs in different culture conditions, we assessed alkaline phosphatase activity, OCT4 expression level, as well as the mRNA expression levels of Sox2, Oct4 and Nanog. As expected, mESCs cultured in Group $\mathrm{c}$ and d yielded round, compact, alkaline phosphatase-stained mESCs colonies (Fig. 6A), indicating a stronger alkaline phosphatase activity and higher self-renew capability than the flat, shapeless, outer area alkaline phosphatase non-stained colonies in Group a and Group b. The results of OCT4 expression showed that mESCs cultured in Group d yielded the most number of OCT4-positive colonies (Fig. 6B, C). Meanwhile, semi-quantitative PCR analysis showed that in group $d$, the RNA expression levels of the core pluripotent-specific genes Oct4, Sox2, and Nanog remained 

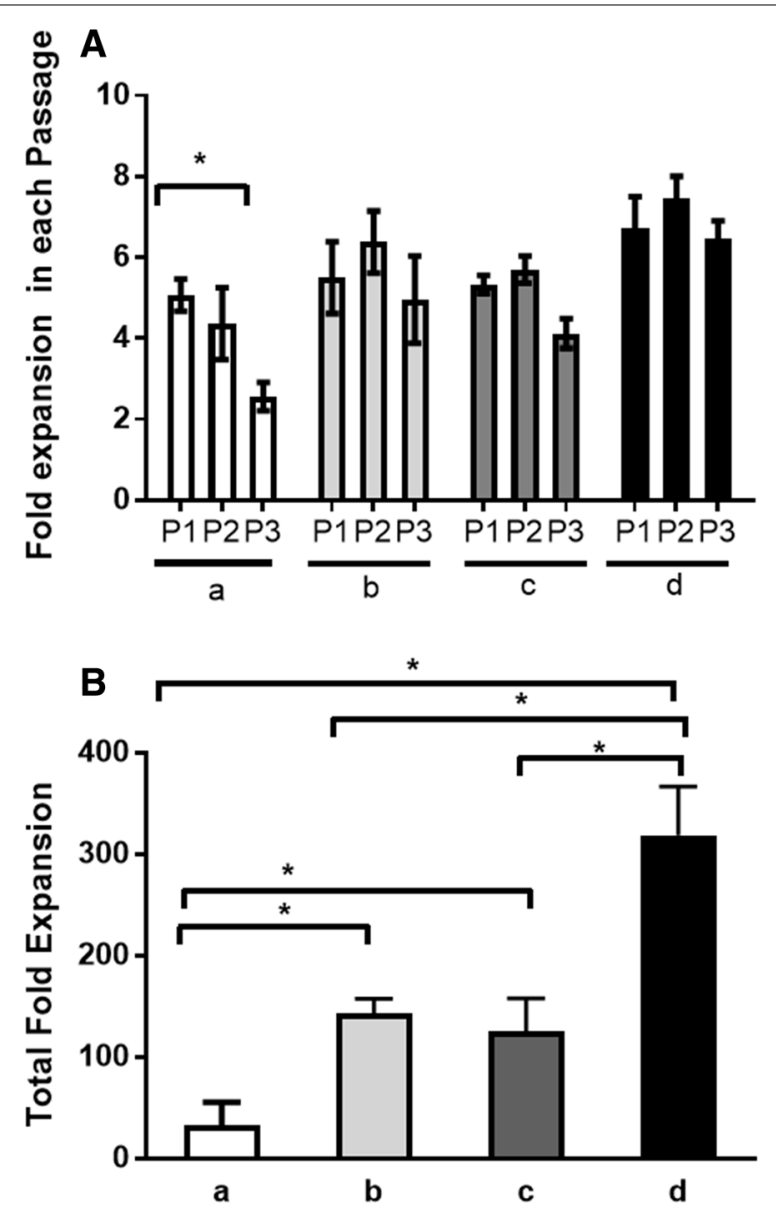

Fig. 4 Synergism of FGF/MEK/ERK signaling and Wnt/ $\beta$-catenin signaling in maintaining $\mathrm{mESC}$ proliferation. The concentration of SB216763, SU5402 and PD0325901 used here was $5 \mu \mathrm{M}, 2 \mu \mathrm{M}$ and $1 \mu \mathrm{M}$. A Comparison of fold expansion in each passage. B Fold expansion of total cells after three passages. Group a (no treatment), Group b (SB216763), Group c (PD0325901 + SU5402), Group d (PD0325901 + SU5402 + SB216763). Error bars are standard deviations $(n=3) .{ }^{*}$ Represents significant difference $(P<0.05)$

stable, indicating that the pluripotency was maintained (Fig. 6D).

The above findings demonstrated that the FGF/ MEK/ERK regulators (SU5402 and PD0325901) and Wnt/ $\beta$-catenin regulator (SB216763) work synergistically to improve proliferation. PD0325901 plays a dominant role in promoting pluripotency of mESCs.

\section{Discussion}

The FGF/MEK/ERK and Wnt/ $/$-catenin signaling pathways have previously been proved to regulate mESCs function (Asuni et al. 2006; Kimelman 2006; MacDonald and $\mathrm{He} 2009$ ). Some published papers have used the combination of FGF/MEK/ERK and Wnt/B-catenin pathway regulators to culture mESCs (Ying et al. 2008; Kiyonari et al. 2010; Turner and Grose 2010; Van der Jeught et al. 2013), but most of them focused on the maintenance of pluripotent markers and the derivation or Germline established of mESCs. The difference in proliferation and pluripotency of mESCs regulated by different pathway was rarely discussed. Here, mESCs were treated with FGF/MEK/ERK and Wnt/ $\beta$-catenin pathway regulators alone and in combination in serum- and feeder-free culture conditions. The results showed that regulators of these two pathways play different roles in the regulatory networks of mESCs.

The differentiation of $\mathrm{mESC}$ involves auto-inductive stimulation of the FGF/MEK/ERK pathway by FGF4 (Kunath et al. 2007). The selective inhibitors SU5402 and PD0325901 were used here to inhibit FGFR tyrosine kinases and MEK, respectively. It has been already proved that the phosphorylation of ERK is dispensable for the differentiation of ESCs (Ma et al. 2016). Previous studies have suggested that ERK is the only downstream targets for MEK (Shaul and Seger 2007). Our studies demonstrated that cells treated with MEK inhibitor PD0325901 alone showed higher SSEA-1 and OCT4 expression level, indicating the promotion of mESCs pluripotency (Figs. 2 and 3). Moreover, PD0325901 also suppresses the expression of Cyclin D1 which leads to lower cell proliferation rate (Fig. 1) (Jin et al. 2011). SU5402 suppresses the activation of signaling pathway downstream of FGFR, not limited to FGF/MEK/ERK pathway (Dvorak et al. 2006). SU5402 also blocks the function of FGF2 which acts as a competence factor in the activin/nodal/TGFb pathway and supports the growth of undifferentiated cells (Rosler et al. 2004; Dvorak et al. 2006). In our study, SU5402 brought out higher cell proliferation rate and low SSEA-1 expression level (Figs. 1 and 2) which was different from PD0325901. Both PD0325901 and SU5402 can decrease phospho-ERK levels; moreover, the combination of these two inhibitors decreases phospho-ERK levels more greatly (Ying et al. 2008; Jin et al. 2011). Consistently, we found that the combination of these two inhibitors promoted both proliferation and pluripotency of mESCs, which is much better than using them alone (Figs. 1 and 3).

Wnt/ $\beta$-catenin pathway regulators such as GSK3 inhibitors are also involved in regulation of pluripotency of mESCs. SB-216763, a fairly selective and potent GSK3 inhibitor dose-dependently, induces transcription of the $\beta$-catenin-dependent gene and achieves the maximum effect at $5 \mathrm{uM}$ (Coghlan et al. 2000). In our study, the addition of SB216763 resulted in high proliferation rate (Fig. 4) and a decrease in SSEA-1 and OCT4 expression levels (Figs. 5 and 6). However, OCT4 in our semi-quantitative PCR showed no difference (Fig. 6D) in contrast to the immunofluorescence result. This makes sense 

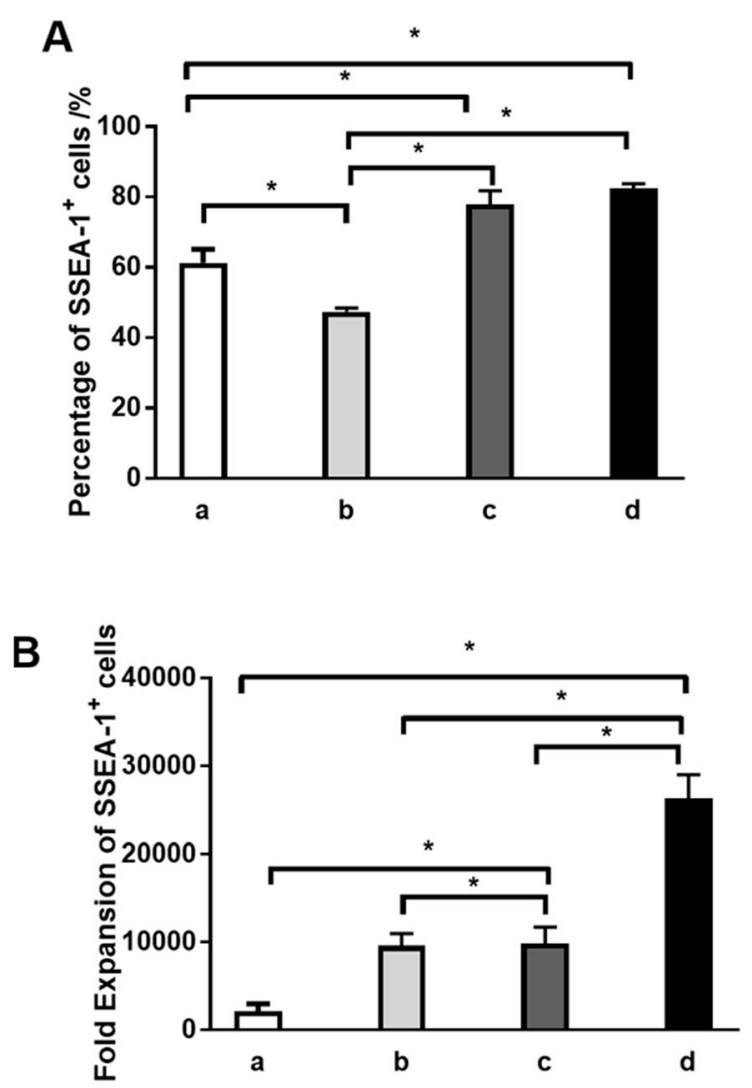

\section{C}
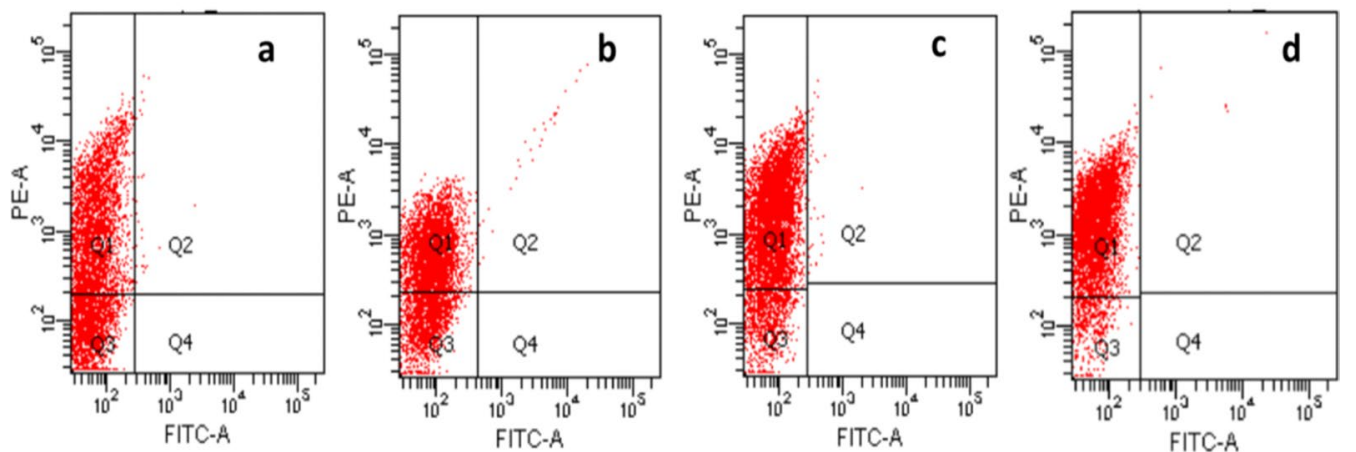

Fig. 5 Synergism of FGF/MEK/ERK signaling and Wnt/ $\beta$-catenin signaling in maintaining mESC pluripotency. The concentration of SB216763, SU5402 and PD0325901 used here was $5 \mu \mathrm{M}, 2 \mu \mathrm{M}$ and $1 \mu \mathrm{M}$. A The percentage of SSEA-1 ${ }^{+}$cells after three passages. B Fold expansion of SSEA- $1^{+}$cells after three passages. C Signal threshold for SSEA-1 ${ }^{+}$cell in flow cytometry. Group a (no treatment), Group b (SB216763), Group C (PD0325901 + SU5402), Group d (PD0325901 + SU5402 + SB216763). Error bars are standard deviations $(n=3)$. * Represents significant difference $(P<0.05)$

because mRNA levels are sometimes inconsistent with protein level, but the result still needs to be confirmed with more sensitive real-time RT-PCR. Kirby et al. demonstrated that SB-216763 can maintain mESCs co-cultured with MEFs in a pluripotent state for up to 2 months in the absence of exogenous LIF, while in our study, SB-216763 induced the differentiation of mESCs under serum- and feeder-free conditions(Kirby et al. 2012). It seems that activation of $\beta$-catenin alone is not sufficient to maintain pluripotency. The off-target effects of inhibitors and cell culture conditions should also be taken into account.

Our studies also demonstrated that the combination of regulators of FGF/MEK/ERK and Wnt/ $\beta$-catenin 


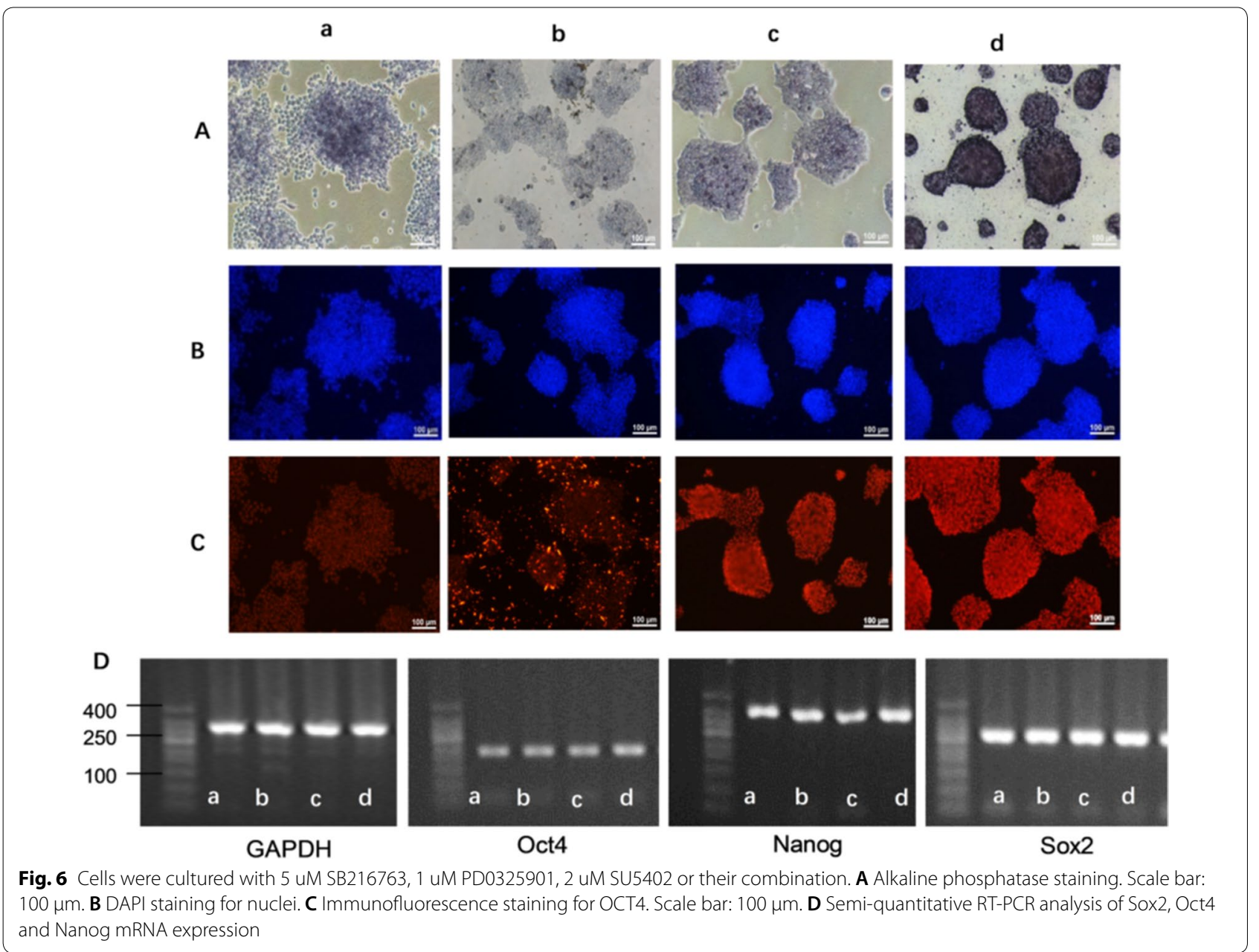

pathways can better maintain the undifferentiated state and promote the proliferation of $\mathrm{mESCs}$ under serumand feeder-free conditions. Yun et al. provide an explanation that the activation of $\mathrm{Wnt} / \beta$-catenin pathway induced the activation of ERK and led to the differentiation of mESCs (Yun et al. 2005). Strooper et al. also showed that Wnt activity can be altered at several steps of the signal transduction pathway by other signaling molecules, including fibroblast growth factors (FGFs) (De Strooper and Annaert 2001). As the FGF/ MEK/ERK pathway regulators can be used to block ERK activity, it seems that FGF/MEK/ERK and Wnt/ $\beta$ catenin pathway may have synergistic effects and our assay result proved this hypothesis. We monitored the proliferation and pluripotency during the culture process up to three passages and found that the proliferation and pluripotency of mESCs treated in two pathway regulators' combination conditions were significantly improved as compared with regulators added alone. The longer culture period such as 1-2 months and more dosages of regulators will be investigated in the further research.

\section{Conclusions}

The results demonstrated that regulators of FGF/MEK/ ERK and Wnt/ $\beta$-catenin pathways play different roles in the regulatory networks of mESCs and their combination can better maintain the undifferentiated state and promote the proliferation of $\mathrm{mESC}$ under serum- and feeder-free conditions. It will provide supports for media design and process control during the in vitro proliferation of mESCs to establish a more efficient culture system for successful clinical applications.

\section{Abbreviations}

mESCs: mouse embryonic stem cell; GSK-3: glycogen synthase kinase-3; EMT: mesenchymal transition; FGFR: fibroblast growth factor receptor; MEK: mitogen-activated protein kinase; ERK: extracellular signal-regulated kinase; NEAA: nonessential amino acids; SSEA-1: stage-specific embryonic antigen-1; PBS: phosphate buffer. 


\section{Authors' contributions}

TZ designed and performed the experiments. TZ, $\mathrm{HC}$ and $\mathrm{YZ}$ drafted the manuscript. WD helped in the research experiments. HC and WT conceived the research. All authors read and approved the final manuscript.

\section{Acknowledgements}

Not applicable.

\section{Competing interests}

The authors declare that they have no competing interests.

\section{Availability of data and materials}

All data generated or analyzed during this study are included in this published article.

\section{Consent for publication}

All authors have read and approved the manuscript before submitting it to bioresources and bioprocessing.

\section{Ethics approval and consent to participate}

Not applicable.

\section{Funding}

There is no funding source.

\section{Publisher's Note}

Springer Nature remains neutral with regard to jurisdictional claims in published maps and institutional affiliations.

Received: 26 January 2019 Accepted: 11 April 2019

Published online: 20 April 2019

\section{References}

Akiyama T (2000) Wnt/beta-catenin signaling. Cytokine Growth Factor Rev 11:273-282

Asuni AA, Hooper C, Reynolds CH, Lovestone S, Anderton BH, Killick R (2006) GSK3alpha exhibits beta-catenin and tau directed kinase activities that are modulated by Wnt. Eur J Neurosci 24:3387-3392

Burdon T, Stracey C, Chambers I, Nichols J, Smith A (1999) Suppression of SHP-2 and ERK signalling promotes self-renewal of mouse embryonic stem cells. Dev Biol 210:30-43

Chen HF, Kuo HC, Chien CL, Shun CT, Yao YL, Ip PL, Chuang CY, Wang CC, Yang YS, Ho HN (2007) Derivation, characterization and differentiation of human embryonic stem cells: comparing serum-containing versus serum-free media and evidence of germ cell differentiation. Hum Reprod 22:567-577

Coghlan MP, Culbert AA, Cross DA, Corcoran SL, Yates JW, Pearce NJ, Rausch OL, Murphy GJ, Carter PS, Roxbee Cox L, Mills D, Brown MJ, Haigh D, Ward RW, Smith DG, Murray KJ, Reith AD, Holder JC (2000) Selective small molecule inhibitors of glycogen synthase kinase-3 modulate glycogen metabolism and gene transcription. Chem Biol 7:793-803

De Strooper B, Annaert W (2001) Where Notch and Wnt signaling meet. The presenilin hub. J Cell Biol 152:F17-F20

Dravid G, Ye Z, Hammond H, Chen G, Pyle A, Donovan P, Yu X, Cheng L (2005) Defining the role of Wnt/beta-catenin signaling in the survival, proliferation, and self-renewal of human embryonic stem cells. Stem Cells 23:1489-1501

Dvorak P, Dvorakova D, Hampl A (2006) Fibroblast growth factor signaling in embryonic and cancer stem cells. FEBS Lett 580:2869-2874

En-Shu LI, Peng XR, Qian QJ (2011) Effect of LIF on the mouse embryo stem cells under serum-free condition. J Zhejiang Sci-Tech Univ 28:96-100

Evans MJ, Kaufman MH (1981) Establishment in culture of pluripotential cells from mouse embryos. Nature 292:154-156

Huang TS, Li L, Moalim-Nour L, Jia D, Bai J, Yao Z, Bennett SA, Figeys D, Wang L (2015) A regulatory network involving beta-catenin, e-cadherin, PI3K/Akt, and slug balances self-renewal and differentiation of human pluripotent stem cells in response to Wnt signaling. Stem Cells 33:1419-1433
Jin C, Samuelson L, Cui CB, Sun Y, Gerber DA (2011) MAPK/ERK and Wnt/ beta-catenin pathways are synergistically involved in proliferation of Sca-1 positive hepatic progenitor cells. Biochem Biophys Res Commun 409:803-807

Kim GJ, Nishida H (2001) Role of the FGF and MEK signaling pathway in the ascidian embryo. Dev Growth Differ 43:521-533

Kimelman DXW (2006) Beta-Catenin destruction complex: insights and questions from a structural perspective. Oncogene 25:7483-7491

Kirby LA, Schott JT, Noble BL, Mendez DC, Caseley PS, Peterson SC, Routledge TJ, Patel NV (2012) Glycogen synthase kinase 3 (GSK3) inhibitor, SB-216763, promotes pluripotency in mouse embryonic stem cells. PLoS ONE 7:e39329

Kiyonari H, Kaneko M, Abe S, Aizawa S (2010) Three inhibitors of FGF receptor, ERK, and GSK3 establishes germline-competent embryonic stem cells of C57BL/6N mouse strain with high efficiency and stability. Genesis 48:317-327

Kleber M, Sommer L (2004) Wnt signaling and the regulation of stem cell function. Curr Opin Cell Biol 16:681-687

Kunath T, Saba-El-Leil MK, Almousailleakh M, Wray J, Meloche S, Smith A (2007) FGF stimulation of the Erk1/2 signalling cascade triggers transition of pluripotent embryonic stem cells from self-renewal to lineage commitment. Development 134:2895-2902

Li J, Wang G, Wang C, Zhao Y, Zhang H, Tan Z, Song Z, Ding M, Deng H (2007) MEK/ERK signaling contributes to the maintenance of human embryonic stem cell self-renewal. Differentiation 75:299-307

Ma X, Chen H, Chen L (2016) A dual role of Erk signaling in embryonic stem cells. Exp Hematol 44:151-156

MacDonald BTTK, He X (2009) Wnt/beta-catenin signaling: components, mechanisms, and diseases. Dev Cell 17:9-26

Nagai A, Hattori T, Hirose M, Ogura A, Nozaki K, Aizawa M, Yamashita K (2014) Mouse embryonic stem cells cultured under serum- and feeder-free conditions maintain their self-renewal capacity on hydroxyapatite. Mater Sci Eng C Mater Biol Appl 34:214-220

Nichols J, Jones K (2017) Derivation of mouse embryonic stem (ES) cell lines using small-molecule inhibitors of Erk and Gsk3 signaling (2i). Cold Spring Harb Protoc 2017:pdb prot094086

Rosler ES, Fisk GJ, Ares X, Irving J, Miura T, Rao MS, Carpenter MK (2004) Longterm culture of human embryonic stem cells in feeder-free conditions. Dev Dyn 229:259-274

Sato N, Meijer L, Skaltsounis L, Greengard P, Brivanlou AH (2004) Maintenance of pluripotency in human and mouse embryonic stem cells through activation of Wnt signaling by a pharmacological GSK-3-specific inhibitor. Nat Med 10:55-63

Sato H, Amagai K, Shimizukawa R, Tamai Y (2009) Stable generation of serumand feeder-free embryonic stem cell-derived mice with full germlinecompetency by using a GSK3 specific inhibitor. Genesis 47:414-422

Shaul YD, Seger R (2007) The MEK/ERK cascade: from signaling specificity to diverse functions. Biochim Biophys Acta 1773:1213-1226

Sumi T, Tsuneyoshi N, Nakatsuji N, Suemori H (2008) Defining early lineage specification of human embryonic stem cells by the orchestrated balance of canonical Wnt/beta-catenin, Activin/Nodal and BMP signaling. Development 135:2969-2979

ten Berge D, Kurek D, Blauwkamp T, Koole W, Maas A, Eroglu E, Siu RK, Nusse R (2011) Embryonic stem cells require Wnt proteins to prevent differentiation to epiblast stem cells. Nat Cell Biol 13:1070-1075

Turner N, Grose R (2010) Fibroblast growth factor signalling: from development to cancer. Nat Rev Cancer 10:116-129

van Amerongen RNR (2009) Towards an integrated view of Wnt signaling in development. Development 136:3205-3214

Van der Jeught M, O'Leary T, Ghimire S, Lierman S, Duggal G, Versieren K, Deforce D, de Sousa Chuva, Lopes S, Heindryckx B, De Sutter P (2013) The combination of inhibitors of FGF/MEK/Erk and GSK3beta signaling increases the number of OCT3/4- and NANOG-positive cells in the human inner cell mass, but does not improve stem cell derivation. Stem Cells Dev 22:296-306

Volarevic V, Ljujic B, Stojkovic P, Lukic A, Arsenijevic N, Stojkovic M (2011) Human stem cell research and regenerative medicine-present and future. Br Med Bull 99:155-168

Volarevic V, Markovic BS, Gazdic M, Volarevic A, Jovicic N, Arsenijevic N, Armstrong L, Djonov V, Lako M, Stojkovic M (2018) Ethical and safety issues of stem cell-based therapy. Int J Med Sci 15:36-45 
Yang S, Lin G, Tan YQ, Deng LY, Yuan D, Lu GX (2010) Differences between karyotypically normal and abnormal human embryonic stem cells. Cell Prolif 43:195-206

Ying QL, Wray J, Nichols J, Batlle-Morera L, Doble B, Woodgett J, Cohen P, Smith A (2008) The ground state of embryonic stem cell self-renewal. Nature 453:519-523

Yu Y, Wang X, Zhang X, Zhai Y, Lu X, Ma H, Zhu K, Zhao T, Jiao J, Zhao ZA, Li L (2018) ERK inhibition promotes neuroectodermal precursor commitment by blocking self-renewal and primitive streak formation of the epiblast. Stem Cell Res Ther 9:2

Yun MS, Kim SE, Jeon SH, Lee JS, Choi KY (2005) Both ERK and Wnt/betacatenin pathways are involved in Wnt3a-induced proliferation. J Cell Sci 118:313-322

Zhang XZ (2010) Modulation of embryonic stem cell fate and somatic cell reprogramming by small molecules. Reprod Biomed Online 21:26-36

\section{Submit your manuscript to a SpringerOpen ${ }^{\circ}$ journal and benefit from:}

- Convenient online submission

- Rigorous peer review

- Open access: articles freely available online

- High visibility within the field

- Retaining the copyright to your article

Submit your next manuscript at $\boldsymbol{\nabla}$ springeropen.com 